$$
\begin{aligned}
& \text { DOE/ER/ } 40150 \ldots 1 / 94 \\
& \text { CONF-970758- }
\end{aligned}
$$

\title{
SUPERCONDUCTING RF CAVITIES AND MAGNETS FOR A 4-TeV ENERGY MUON COLLIDER
}

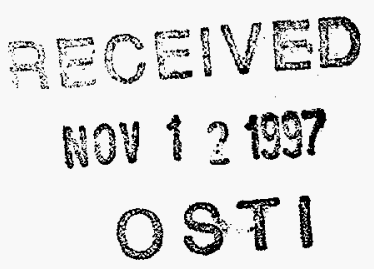

Quan-Sheng Shu ${ }^{1,2}$, M. Green ${ }^{3}$, D. Neuffer ${ }^{4}$, D. Summers ${ }^{5}$

S. Simrock ${ }^{6}$, E. Willen

'Thomas Jefferson National Accelerator Facility, Newport News, VA 23606

${ }^{2}$ Northrop-Grumman Co. Bethpage, NY 11714

${ }^{3}$ Lawrence Berkeley National Lab, Berkeley, CA 94720

${ }^{4}$ Fermi National Accelerator Lab, Batavia, IL 60510

${ }^{5}$ University of Mississippi, Oxford. MS 38677

${ }^{6}$ DESY, Hamburg, D-22603 Germany

${ }^{7}$ Brookhaven National Lab, Upton, NY 11937

\section{ABSTRACT}

The accelerators must take the muon beams from $\sim 100 \mathrm{MeV}$ to $2 \mathrm{TeV}$ energies within the muon lifetime for a $4 \mathrm{TeV}$ energy muon collider. These constraints plus the muon decay heating seriously challenge the designs of the superconducting RF (SRF) cavities and magnets in the accelerators and collider ring. The multiple superconducting recirculation linac and the very rapid-cycling superconducting synchrotron approach are both studied. We briefly introduce the technical considerations and preliminary designs of the SRF systems and magnets.

\section{INTRODUCTION}

Muon colliders can provide strong potential advantages in high-energy physics, but also present serious technical challenges, as described in the Snowmass feasibility study'. A muon collider would use the superconducting RF (SRF) cavities for accelerating and superconducting (SC) magnets for bending the $\mu$-beams throughout the machine. The central difficulty in the $\mu^{+}-\mu^{-}$collider is the muon decay, with a lifetime of $2.2 \times 10^{-6} \gamma_{\mu} \mathrm{s}$ (where $\gamma_{\mu}=E_{\mu} / m_{\mu} c^{2}$ ) that implies a requirement for very rapid increases in muon energies. At the design luminosity, the $\mathrm{SC}$ dipoles and quadrupoles must contain muon beams (up to 


\section{DISCLAMIER}

Portions of this document may be illegible in electronic image products. Images are produced from the best available original document. 


\section{DISCLAIMER}

This report was prepared as an account of work sponsored by an agency of the United States Government. Neither the United States Government nor any agency thereof, nor any of their employees, makes any warranty, express or implied, or assumes any legal liability or responsibility for the accuracy, completeness, or usefulness of any information, apparatus, product, or process disclosed, or represents that its use would not infringe privately owned rights. Reference herein to any specific commercial product, process, or service by trade name, trademark, manufacturer, or otherwise does not necessarily constitute or imply its endorsement, recommendation, or favoring by the United States Government or any agency thereof. The views and opinions of authors expressed herein do not necessarily state or reflect those of the United States Government or any agency thereof. 
$2 \times 10^{12}$ muons per bunch) that will deposit over $1.8 \mathrm{~kW}$ of energy per meter into the storage ring.

First, we introduce a 20-Tesla $\left(\mathrm{T}\right.$ ) hybrid capture solenoid system ${ }^{2}$ (combining a Bitter type water-cooled solenoid with a superconducting solenoid) that captures the pions and transfers the pions to a decay and phase rotation channel producing muons. Muons will then be accelerated in SRF accelerating structures. To do so, we have developed two accelerating scenarios. One of the options is a Rapid Cycling Synchrotron (RCS) ${ }^{3}$, where two hybrid rings ( $2200 \mathrm{~m}$ radius) of fixed $\mathrm{SC}$ magnets alternating with iron magnets ramping at $200 \mathrm{~Hz}$ and $330 \mathrm{~Hz}$ between full negative to full positive field bending the muons. Muons are given $25 \mathrm{GeV}$ of $\mathrm{RF}$ energy $(700 \mathrm{MHz})$ per orbit by accelerating cavities. As an alternative we also discuss another option to $\mathrm{RCS}$, where three recirculating superconducting linacs (respectively with energies reaching $70 \mathrm{GeV}$ (with $350 \mathrm{MHz}$ SRF), $250 \mathrm{GeV}(800 \mathrm{MHz})$ and $2000 \mathrm{GeV}(1300 \mathrm{MHz}))$ are used in a sequence of four recirculating linacs (RLAs) ${ }^{4}$, each of which increases beam energy by $\sim$ an order of magnitude, they accelerate beams up to $2 \mathrm{TeV}$ for injection into a collider ring.

At $2 \mathrm{TeV}$ the mean muon lifetime is $41.6 \mathrm{~ms}$. To achieve high luminosity (higher number of turns and shorter orbit), the dipole should be over $8 \mathrm{~T}$ carrying muon over 1000 turns in a short-diameter orbit'.

\section{SC MAGNETS FOR MUON CAPTURES}

The pions produced by a target ${ }^{1}$ must be captured by solenoid magnets during their decay into muons. A possible layout of a 20-T hybrid solenoid magnet with a clear bore of $150 \mathrm{~mm}$ is shown in Fig. 1, which is designed to capture particles with a transverse momentum of $225 \mathrm{MeV} / \mathrm{c}$ or less. The hybrid magnet option was selected for the following reasons: 1) The operating power for the water cooled solenoid is substantially lower if a superconducting outer-magnet is used. 2) The current density in the water-cooled Bitter solenoid can be low enough to insure that its lifetime will be long enough. (A reasonable lifetime goal might be 25000 hours.) 3) Additional space inside the Bitter solenoid can be made available for a heavy metal water-cooled shield. This reduces the incident energy from

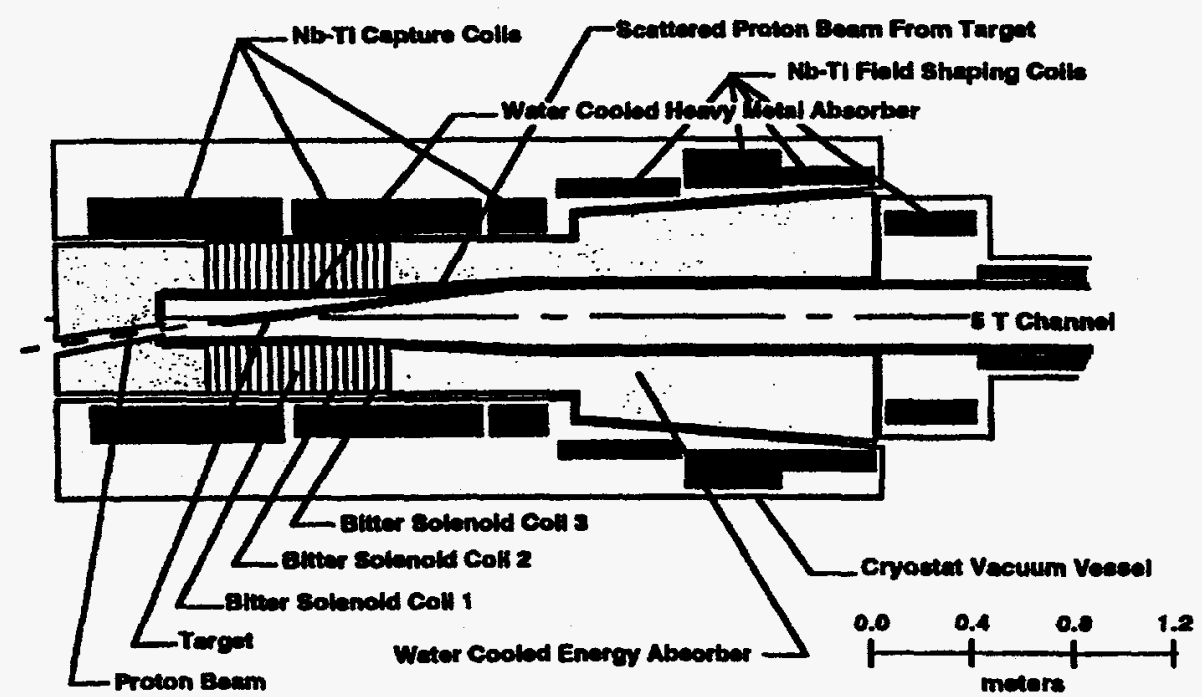

Figure 1. A 20T hybrid capture solenoid with a transfer solenoid system of $5 T$ in phase rotation section (inside is a tilted target). 
the target into the water-cooled solenoid and the surrounding superconducting solenoid.

The water-cooled Bitter solenoid insert has an inner radius of $120 \mathrm{~mm}$. The extra inner bore radius allows a heavy metal (tungsten or some other high $\mathrm{Z}$, high density metal) shield that is $30 \mathrm{~mm}$ thick to be inserted around the target region. The Bitter solenoid insert outer radius has been set at $345 \mathrm{~mm}$. The cryostat of the SC outer-magnet (solenoid) starts at a radius of $370 \mathrm{~mm}$.

The SC outer-magnet coil alone is designed to produce a central field of about $7.5 \mathrm{~T}$. Operating under this condition, the outer-magnet solenoid can be made from $\mathrm{Nb}-\mathrm{Ti}$ operating at $2.0 \mathrm{~K}$. The outer-magnet has three coils with an inner radius of $400 \mathrm{~mm}$. The outer radius of these coils is about $540 \mathrm{~mm}$. The peak magnetic field in the outer-magnet coil is about $8.3 \mathrm{~T}$ when the coils are fully powered.

Other superconducting solenoids downstream from the outer-magnet coils form the transition region that shapes the magnetic field between the target and the phase rotation system. The decay of the pions to muons will occur at the $5 \mathrm{~T}$ region.

\section{RECIRCULATION SRF ACCELERATOR}

In a muon accelerator the decay and acceleration rates require a small decay loss that means $\mathrm{dE} / \mathrm{ds} \gg \mathrm{m}_{\mu} \mathrm{c}^{2} / \mathrm{L}_{\mu}=0.16 \mathrm{MeV} / \mathrm{m}$ (including all lengths), which is relatively large, but can be reached in multipass systems with moderately high gradient.

\section{SRF Acceleration Systems}

The basic accelerating unit in this scenario is the recirculation linear accelerator (RLA), which consists of two linacs with return arcs in a racetrack configuration. The beams are accelerated and returned for several passes in the same linacs, but with separate return arcs (10-20 turns). There are four RLAs, each of which increases beam energy by $\sim$ an order of magnitude, and which accelerates beam up to $2 \mathrm{TeV}$ for injection into a collider ring ${ }^{4}$. Figure 2 shows a conceptual overview of a 4-RLA system. The RLA permits economic multipass

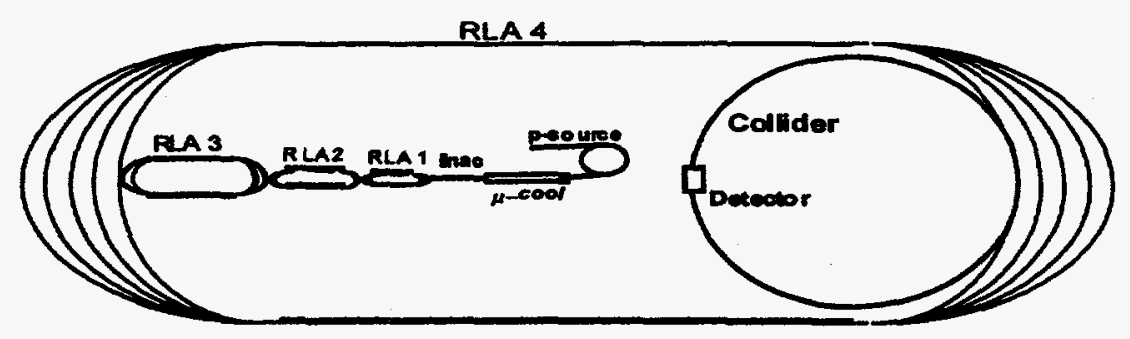

Figure 2. Overview of a $\mu^{+}-\mu^{-}$collider system.

Table 1. Parameters of a 4-RLA $\mu$-accelerating system.

\begin{tabular}{ccccc}
\hline & RLA 1 & RLA 2 & RLA 3 & RLA 4 \\
\hline Beam energy (GeV) & $1 \rightarrow 9.6$ & $9.6 \rightarrow 70$ & $70 \rightarrow 250$ & $250 \rightarrow 2000$ \\
RF frequency (MHz) & 100 & 350 & 800 & 1300 \\
$N$ turns & 9 & 11 & 12 & 16 \\
$\mathrm{~V}_{\mathrm{ti}} /$ turn & 1.0 & 6 & 16 & 11.2 \\
$\mathrm{~L}_{\text {turm }}\left(2 \mathrm{~L}_{\text {linac }}+2 \pi \mathrm{R}\right)(\mathrm{km})$ & 0.26 & .095 & 2.32 & 12.6 \\
Beam Survival & $91 \%$ & $94.8 \%$ & $97.6 \%$ & $96.4 \%$ \\
$\sigma_{\mathrm{zheum}}(\mathrm{cm})$ & $8.3 \rightarrow 4.8$ & 1.3 & 0.6 & 0.3 \\
Cavity temp. K & & 4.2 & 2 & 2 \\
\hline
\end{tabular}


acceleration, but the separate transport for each turn with cost and complexity limits the number of turns to $\sim 10-20$ per RLA. In this scenario, RF systems at 350,800 and 1300 $\mathrm{MHz}$ are SRF cavities. Table 1 gives the main parameters of the SRF system.

If the total $R F$ voltage and beam current are fixed, the use of pulsed RF can reduce the 'cryogenic cost' and allow a higher $\mathrm{E}_{\mathrm{acc}}$.

\section{SRF Cavities and SC Magnets}

In RLA4, the muon energy increases from $250 \mathrm{GeV}$ to $2000 \mathrm{GeV}$. As a baseline design $25 \mathrm{MV} / \mathrm{m}\left(\mathrm{Q}_{0}=5 \times 10^{9}\right)$ at $2 \mathrm{~K}$ and 16 turns are chosen that requires about $112 \mathrm{GV}$ per turn from cavities, or $4.5 \mathrm{~km}$ of active linac. Encouraged by the pulsed test results of the TESLA cavities, it is possible to use a higher $E_{a c c}$. If $35 \mathrm{MV} / \mathrm{m}$ becomes realistic, the linac could be reduced to $3.2 \mathrm{~km}$. For the $1300 \mathrm{MHz}$ SRF, 16 passes and $15 \mathrm{~Hz}-\mathrm{RF}$ pulses, the HOM power is $\sim 300 \mathrm{~W} / \mathrm{m}$. One alternative will be to enlarge the aperture of the cavity from existing $70 \mathrm{~mm}$ to $102 \mathrm{~mm}$. That will reduce the HOM mode damping requirements by a factor of $50 \%{ }^{6}$. Fig. 3 shows a modified arrangement of the TESLA type cryomodule and Fig. 4 shows a cross-section of the multipass superconducting magnets.

Because of larger apertures and longer bunches, HOM power is expected to decrease as $\sim 1 / \lambda_{\mathrm{RF}}^{3}$ so HOM excitation at $800 \mathrm{MHz}$ and $350 \mathrm{MHz}$ should be much less (respectively, $-60 \mathrm{~W} / \mathrm{m}$ and $2 \mathrm{~W} / \mathrm{m}$ in this scenario). Decay losses at this intensity are $\sim 16 \mathrm{~W} / \mathrm{m}$. We require that the cryogenic system tolerate $\sim 10 \%$ of decay losses at $2 \mathrm{~K}(1.6 \mathrm{~W} / \mathrm{m})$ with the remainder absorbed at higher temperature.

The $800 \mathrm{MHz}$ RLA3 requires $16 \mathrm{GV}$ of SRF or $1.07 \mathrm{~km}$ of linac (12 turns) at 15 $\mathrm{MV} / \mathrm{m}\left(\mathrm{Q}_{0}=5 \times 10^{9}\right)$ and $2 \mathrm{~K}$. The $350 \mathrm{MHz}$ RLA2 requires $6 \mathrm{GV}$ of SRF cavities, or $600 \mathrm{~m}$ (11 turns) at $10 \mathrm{MV} / \mathrm{m}$ and $4 \mathrm{~K}$. Such values have been achieved in smaller testing structures. Figure 5 shows a candidate of the $350 \mathrm{MHz}$ SRF cryomodule from CERNLEPII .

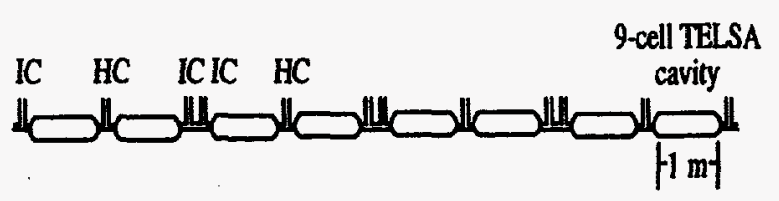

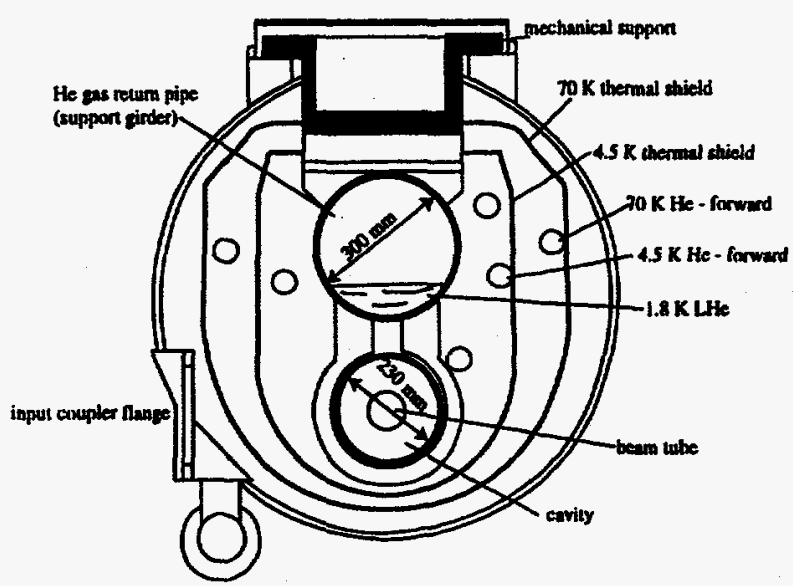

Figure 3. A cryomodule based on the TESLA cavities (couplers - IC and HOM couplers - HC).

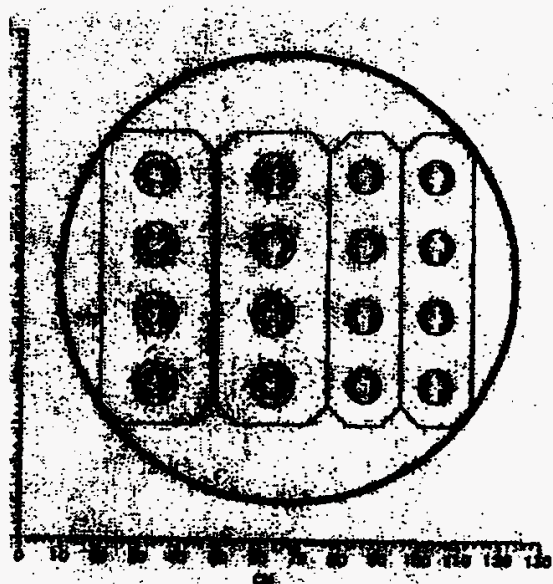

Figure 4. A cross-section of the multipass superconducting magnets. 


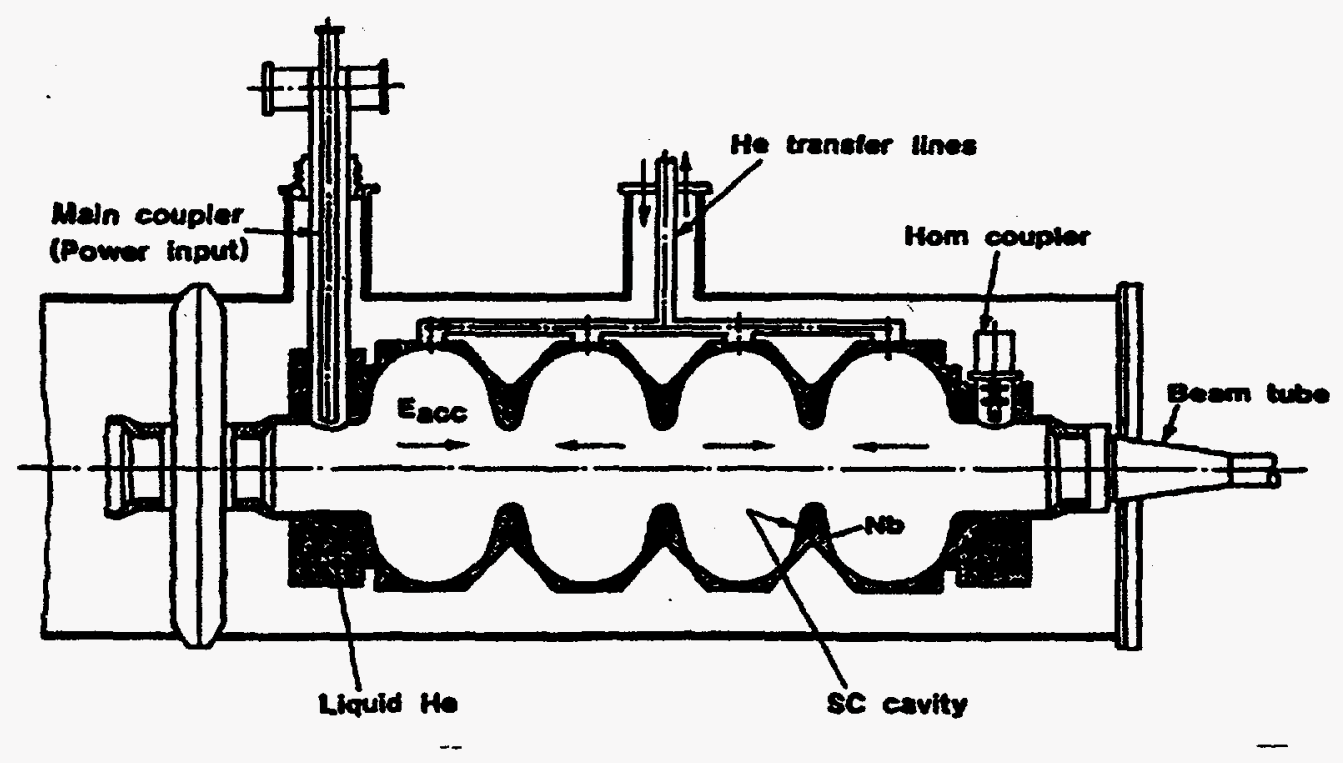

Figure 5. A candidate of the RLA2 cryomodule, based on a CERN $350 \mathrm{MHz}$ SRF cavity.

Table 2. RF System and RF Power

\begin{tabular}{llll}
\hline & RLA2 & RLA3 & RLA4 \\
\hline RF pulse length, $\mu \mathrm{s}$ & 35 & 84.2 & 672 \\
Loaded Q to min. & $1 \times 10^{6}$ & $1 \times 10^{6}$ & $1 \times 10^{6}$ \\
$\Delta$ Eacc/Eacc & 0.018 & 0.027 & 0.033 \\
Average I, mA & 100 & 45.6 & 7.6 \\
Available RF Power, $\mathrm{kW} / \mathrm{m}$ & 200 & 200 & 400 \\
Voltage drop & 0.086 & 0.12 & $\sim 0.0$ \\
RF on - cryogenic loss, $\mathrm{W} / \mathrm{m}$ & 119 (at 4K) & 71 (at $2 \mathrm{~K})$ & 78 (at $2 \mathrm{~K})$ \\
Ave. wall power for RF, $\mathrm{kW} / \mathrm{m}$ & 5.2 & 2.6 & 5.25 \\
\hline
\end{tabular}

\section{RF Power Requirements}

The RF power requirements are dominated by the power needed for the acceleration of the beams. Additional power is required for RF controls. The control power needed depends on the magnitude of perturbations to be controlled to pass the muons 10 times through a pair of linacs. Table 2 lists the RF powers needed.

\section{RAPID CYCLING SYNCHROTRON}

Rapid-cycling approaches require innovations in magnet designs and layouts, but could be more affordable than a RLA version. Fig. 6. is a schematic layout of RCS and table 3 summarizes the parameters of the sub-systems.

$100 \mathrm{MeV}-2 \mathrm{GeV}$ Using RF=2GV: A single pass $2 \mathrm{GV}$ linac is used.

$2 \mathrm{GeV}-25 \mathrm{GeV}$ Using RF = 2.5 GV/turn: This is the first recirculating ring and has $2.5 \mathrm{GV}$ of $100 \mathrm{MHz}$ RF. The superconducting magnets with 10 bores (each with a different fixed field) are used.

$25 \mathrm{GeV}-250 \mathrm{GeV}$ Using $\mathrm{RF}=6 \mathrm{GV} /$ turn: This stage uses a single ring of fast ramping $\cos \theta$ dipoles. Thin stranded copper conductor is used at room temperature to achieve a 4 Tesla field. The low duty cycle is exploited to keep the $I^{2} R$ losses reasonable. A $6 \mathrm{GV}$ of $350 \mathrm{MHz}$ SRF system is distributed around the ring and accelerates the muons from $25 \mathrm{GeV}$ to $250 \mathrm{GeV}$ in 40 orbits. 


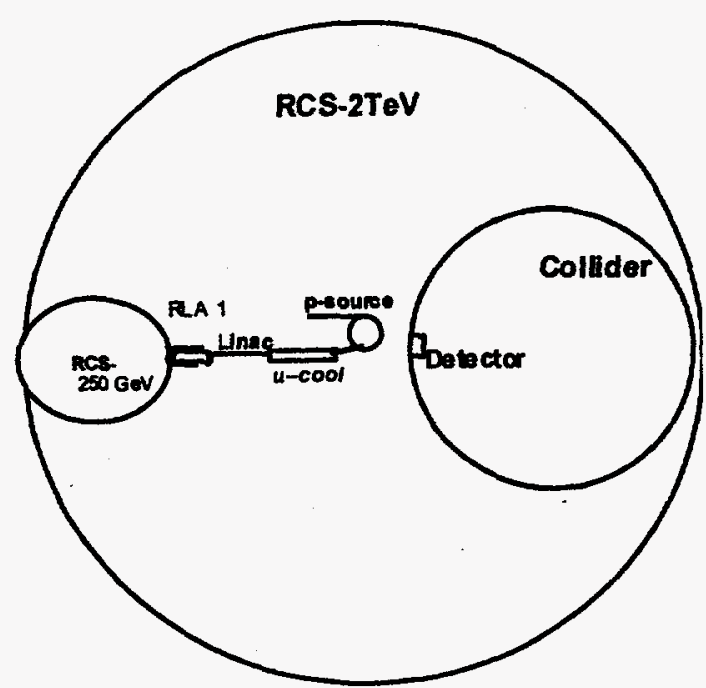

Figure 6. The Rapid -Cycling scenario of a muon accelerator and collider system

Table 3. The main parameter of the RCS system

\begin{tabular}{|c|c|c|c|c|}
\hline & Linac & RLA & RCS1 & RCS2 \\
\hline$\overline{E(G e V)}$ & $0.1 \rightarrow 2$ & $2 \rightarrow 25$ & $25 \rightarrow 250$ & $250 \rightarrow 2400$ \\
\hline$f_{t}(M H z)$ & $10 \rightarrow 100$ & 100 & 350 & 800 \\
\hline $\mathbf{N}_{\text {tums }}$ & 1 & 10 & 40 & 86 \\
\hline$V_{n}(G V)$ & 2 & 2.5 & 6 & 32 \\
\hline$C_{\text {tum }}(\mathrm{km})$ & 0.4 & 0.36 & 2.3 & 14 \\
\hline$\tau(\mathrm{ms})$ & 0.0013 & 0.012 & 0.307 & 4.0 \\
\hline$\sigma_{b e m}(\mathrm{~cm})$ & $100 \rightarrow 10$ & 3 & 1 & 0.5 \\
\hline Survival & $93 \%$ & $92 \%$ & $85 \%$ & $82 \%$ \\
\hline
\end{tabular}

$-60 \%$ survival over full cycle

$260 \mathrm{GeV}-2 \mathrm{TeV}$ Using $\mathrm{RF}=25 \mathrm{GV} / \mathrm{turn}$ : In the stage, we have two hybrid rings (2200m radius) of fixed superconducting magnets alternating with iron magnets ramping at $200 \mathrm{~Hz}$ between full negative and full positive field to bend the muons from the lower injection-energy to the higher extraction energy. Muons are given $25 \mathrm{GeV}$ of $\mathrm{RF}$ energy ( $800 \mathrm{MHz}$ ) per orbit (tatol: 96 orbits). The SRF cavities are divided into multiple sections as at CERN-LEPII, so that magnetic fields and beam energies will match around the rings.

\section{SC MAGNETS FOR COLLIDER RING}

\section{Special Considerations}

Two factors govern the design of the collider ring magnets for a muon collider. (1) The decay of the muons within the ring can deposit up to $2 \mathrm{~kW}$ of beam energy per meter into the magnet bore in the form of high energy electrons, positrons and gamma rays. One must keep the muon decay products from depositing their energy into the superconductor of the collider ring magnets. (2) The luminosity at the collision point is inversely proportional to the ring circumference squared and it is inversely proportional to the beam size function squared. In order to get the circumference of the ring as small as possible, dipoles with a high central field are desirable. The strength of the quadrupoles should in some way be proportional to the collider ring dipole central field. A small beam size means that the beam beta function at the collision point must be very small. As a result, the focusing 
quadrupoles around the collision point must be strong with a large aperture. (The beam beta function in these quadrupoles is often very large in at least one direction.) Table 4 lists the muon decay parameters ${ }^{5}$,

\section{Magnet Design with an Absorbing Bore Tube}

As shown in Fig. 7, to attenuate the decay product power by three orders of magnitude, about $65 \mathrm{~mm}$ of tungsten shield is required. Only about $1.8 \mathrm{~W}$ per meter will then be deposited into the superconducting coil while the remainder of the beam decay power will

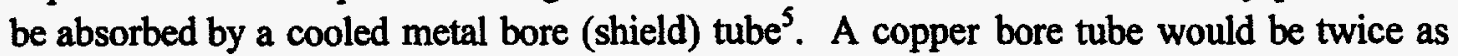
thick. The primary problem with the large aperture magnet design is the large forces because of the high magnetic fields and the large inner coil radius. These forces scale as the square of the central field times the inner coil radius. Test dipoles with a coil radius of 25 $\mathrm{mm}$ have been built and operated at central field as high as $10.2 \mathrm{~T}$ at a temperature of $1.8 \mathrm{~K}$. Fig. 7 is a schematic layout of the magnet.

Table 4. Muon Decay Parameters in Various Components of a RLA scenario

\begin{tabular}{lccccc}
\hline Components & $\begin{array}{l}\text { Peak Energy } \\
(\mathrm{GeV})\end{array}$ & $\begin{array}{l}\text { No. of } \\
\text { Turns }\end{array}$ & $\begin{array}{l}\text { Decay Rate } \\
\left(\mu \mathrm{s}^{-1}\right) \times 10^{13}\end{array}$ & $\begin{array}{l}\text { Decay Power } \\
(\mathrm{kW})\end{array}$ & $\begin{array}{l}\text { Decay Power } \\
\text { per unit } \mathrm{L}\left(\mathrm{W} \mathrm{m} \mathrm{m}^{-1}\right)\end{array}$ \\
\hline First Ring & 9.6 & $-\mathrm{NA}-$ & 1.9 & 0.6 & $-\mathrm{NA}-$ \\
Second Ring & 79 & 11 & 1.2 & 3.6 & 1.64 \\
Third Ring & 250 & 12 & 0.8 & 19.7 & 1.75 \\
Fourth Ring & 2000 & 16 & 0.4 & 36.8 & 1.26 \\
Collider Ring & 2000 & 1000 & 13.1 & 14600 & 1840 \\
\hline
\end{tabular}

\section{The Split Coil Design}

In order for the muon decay products to leave the storage ring without colliding with the coil or a beam tube liner, there must be no material on the mid-plane of the magnet. The muon decay products must pass the superconducting coil without interacting with any material. When the decay products are absorbed, they have to be absorbed in a way that prevents back scatter into the superconducting coils. A dipole using the split coil

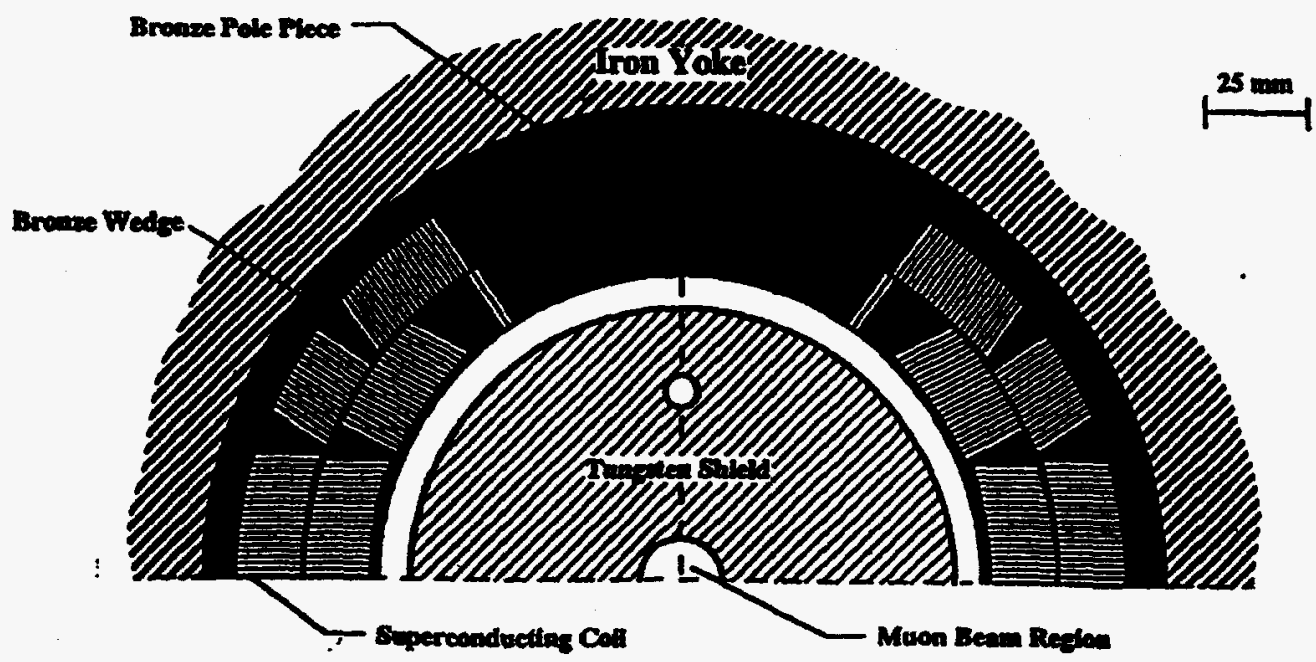

Figure 7. A cosine theta coil structure (muon decay energy is absorbed by a tungsten shield (65mm-thick). 


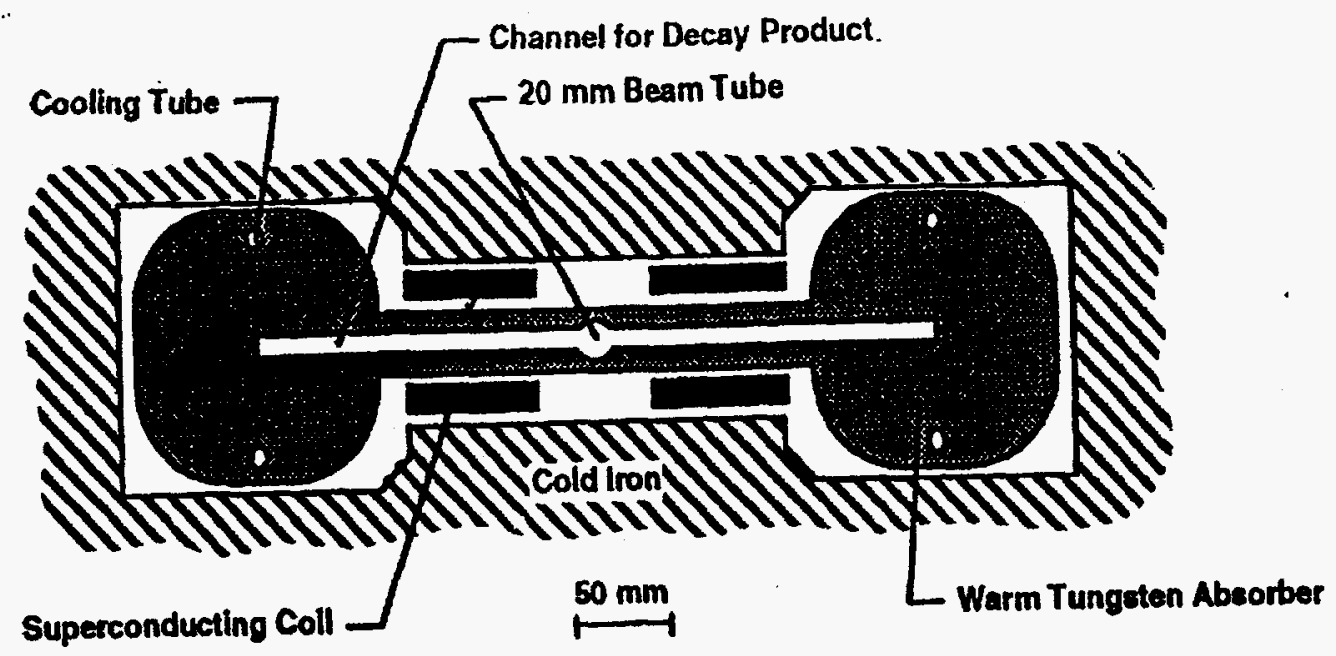

Figure 8. Separated coils on the mid-plane with a warm absorber for the muon decay products (an $\mathrm{H}$ magnet).

configuration can be fabricated in either a $\mathrm{C}$ or $\mathrm{H}$ configuration. Configured as an $\mathrm{H}$ magnet (see Fig. 8), the cold iron dimensions would be about $1060 \mathrm{~mm}$ wide by $700 \mathrm{~mm}$ high. The design shown in Fig. 8 has large forces that pull the coils together (across the mid-plane). The forces also push the coils apart parallel to the $x$-axis. In a cold iron configuration, the coil must be attached directly to the iron pole. Fig. 8 does not show this connection.

\section{ACKNOWLEDGMENT}

Many thanks are given to colleagues of the muon collaboration. Q. S. Shu also sincerely appreciate $S$. Corneliussen and $P$. Kneisel for carefully reviewing this paper, and S. Spata and T. Wang for editing it.

\section{REFERENCE}

[1] (A) $\mu^{+} \mu^{-}$Collider - A Feasibility Study, BNL-52503, Fermi-Lab-Conf.-96-092, LBNL38946, Muon Collider Collaboration, presented at the Snowmass workshop (1996). (B) D. Neuffer, to be published in NIM A (1996).

[2] M. A. Green, et. al., LBNL-39107, Lawrence Berkeley National Lab, Berkeley CA $94720,1997$.

[3] D. Summers, et. al., International Particle Accelerator Conference - 97, Vancouver Canada 1997.

[4] (A) Q.-S. Shu, et. al., International Particle Accelerator Conference - 97, Vancouver Canada 1997.

(B) Q-S. Shu for the TESLA Collaboration, in Advances in Cryogenic Engineering, $P$. Kittel, ed. Vol. 41 A, p. 827 (1996).

[5] M. A. Green, et. al., LBNL-39106, Lawrence Berkeley National Lab, Berkeley CA $94720,1997$.

[6] J. Sekutowicz, Private communication, DESY, Hamburg Germany, May 1997.

[7] W. Weingarten, Private communication, CERN, Geneva Switzerland, September 1996. 